\title{
Quantifying the Feeding Periods Required by Corn Flea Beetles to Acquire and Transmit Pantoea stewartii
}

\author{
B. Menelas, Former Graduate Research Assistant, Department of Plant Pathology, Iowa State University, Ames \\ 50011; C. C. Block, United States Department of Agriculture-Agricultural Research Service, North Central Plant \\ Introduction Station, Ames, IA, 50011; and P. D. Esker, Graduate Research Assistant, and F. W. Nutter, Jr., Profes- \\ sor, Department of Plant Pathology, Iowa State University, Ames
}

\begin{abstract}
Menelas, B., Block, C. C., Esker, P. D., and Nutter, F. W., Jr. 2006. Quantifying the feeding periods required by corn flea beetles to acquire and transmit Pantoea stewartii. Plant Dis. 90:319324.

The feeding periods required by corn flea beetles to acquire and transmit Pantoea stewartii were investigated in the Stewart's disease of corn pathosystem. To quantify the effect of acquisition feeding period on percentage of acquisition, field-collected corn beetles were allowed to feed for $6,12,2436,48$, and $72 \mathrm{~h}$ on corn seedlings previously inoculated with a rifampicin- and nalidixic acid-restraint strain of $P$. stewartii. Acquisition of $P$. stewartii by corn flea beetles was considered positive if the rifampicin- and nalidixic acid-marked strain was recovered on selective media. To quantity the effect of transmission feeding period on percent transmission of $P$. stewartii by corn flea beetles, $P$. stewartii-infested corn flea beetles were allowed to feed on healthy corn seedlings for periods of $3,6,12,24,36,48$, and $72 \mathrm{~h}$. After the appropriate transmission feeding period, leaf tissues surrounding the sites of feeding scars were cultured for the presence of the $P$. stewartii-marked strain. Transmission of $P$. stewartii was considered positive if the marked strain was recovered on selective media. Acquisition of $P$. stewartii occurred within 6 $\mathrm{h}$ and the percentage of corn flea beetles that had acquired $P$. stewartii after $72 \mathrm{~h}$ ranged from 68 to $94 \%$. The change in $P$. stewartii acquisition by corn flea beetles (Y) with respect to acquisition feeding period $(\mathrm{X})$ was best described by the Gompertz model, with $R^{2}$ values ranging from 91 to $99 \%$. The mean time for acquisition by $50 \%$ of the corn flea beetles was $36.5 \pm 11.6 \mathrm{~h}$. The minimum transmission feeding time required for corn flea beetles to transmit $P$. stewartii following a 48-h acquisition feeding period was less than $3 \mathrm{~h}$. The percent transmission of $P$. stewartii by corn flea beetles was nearly $100 \%$ after a 48 -h transmission feeding period and was $100 \%$ by $72 \mathrm{~h}$. Among population growth models evaluated, the monomolecular model best described the relationship between percent transmission $(\mathrm{Y})$ and transmission feeding periods $(\mathrm{X})$, with $R^{2}$ values of up to $84 \%$. However, a nonlinear form of the monomolecular model better quantified the relationship between percent transmission and transmission feeding period, because pseudo$R^{2}$ values ranged between 98.1 and $99.5 \%$. The predicted transmission feeding time required for $50 \%$ of $P$. stewartii-infested corn flea beetles to transmit the pathogen was $7.6 \pm 0.87 \mathrm{~h}$. These results suggest that the corn flea beetle is a highly efficient vector that can quickly acquire and transmit $P$. stewartii, thereby requiring insecticide seed treatments and foliar insecticides that act quickly to prevent corn flea beetles from acquiring and transmitting $P$. stewartii to corn plants.
\end{abstract}

Additional keywords: Chaetocnema pulicaria

Stewart's disease of corn, caused by Pantoea (Erwinia) stewartii subsp. stewartii (Smith) Dye (11,17,29,31), has significant economic implications for sweet corn and seed corn producers in the U.S. Corn Belt (21). Phytosanitary regulations are in place to prevent the introduction of $P$. stewartii into countries where this pathogen has not been reported to occur (1). The bacterium is a nonmotile, non-sporeforming, capsule-forming gram-negative rod that is approximately 0.4 to $0.8 \mu \mathrm{m}$ by

Corresponding author: F. W. Nutter, Jr.

E-mail: fwn@iastate.edu

Accepted for publication 15 October 2005.

DOI: 10.1094/PD-90-0319

(C) 2006 The American Phytopathological Society
0.9 to $2.2 \mu \mathrm{m}$ in size $(22,23,29)$. P. stewartii is an insect-borne pathogen. The corn flea beetle Chaetocnema pulicaria Melsheimer (order: Coleoptera, family: Chrysomelidae) is the primary vector of $P$. stewartii. Corn flea beetles are approximately $1.8 \mathrm{~mm}$ in size and typically are shiny and black with enlarged hind femurs $(7,22)$.

In addition to being an insect-borne pathogen, another potential source of inoculum is seed transmission. Early reports suggested that seed transmission played an important role in the occurrence of Stewart's disease $(24,30)$. However, recent studies by Michener et al. (18), Block et al. (24), and Khan et al. (12) all have shown that the risk of seed-to-seedling transmission of $P$. stewartii is extremely low. In their study, Khan et al. (12) grew 75,000 plants from seed that was harvested from $P$. stewartii- infected plants and did not find any seedto-seedling transmission of $P$. stewartii in the test plants; however, they did not determine the actual percentage of $P$. stewartii-infected (or infested) seed. Both Michener et al. (18) and Block et al. (2-4), however, adjusted their estimates of seedto-seedling transmission to account for the percentage of infected seed in a seedlot. Michener et al. (18) reported that seed-toseedling transmission was $0.038 \%$ after testing 58,300 kernels obtained from infected plants. Studies by Block et al. (2-4) revealed only $0.14 \%$ seed-to-seedling transmission of $P$. stewartii from infected kernels harvested from artificially inoculated plants (29 of 19,735 seed), and $0.022 \%$ (1 of 4,563) seed-to-seedling transmission from $P$. stewartii-infected kernels harvested from naturally infected plants (3).

After conducting several field experiments during the 1920s in Maryland and Maine using multiple $P$. stewartii-infected seed lots, Rand and Cash $(25,26)$ were convinced that the onset and secondary spread of $P$. stewartii in the field suggested the involvement of an insect vector. Later, the corn flea beetle ( $C$. pulicaria) was shown to be the primary vector of $P$. stewartii in the Stewart's disease of corn pathosystem (8). In spite of the fact that the corn flea beetle was shown to be the principal vector of $P$. stewartii as early as 1934, little is actually known about the feeding times required for successful acquisition and transmission of the pathogen. This knowledge not only would help to improve our understanding of the biology of this pathosystem, but also may help in developing more resistant genotypes or insecticide programs to better manage corn flea beetle populations by preventing the acquisition and transmission of $P$. stewartii. The objectives of this study were to quantify the feeding periods required by the corn flea beetles for both acquisition and transmission of $P$. stewartii.

\section{MATERIALS AND METHODS}

The susceptible sweet corn cv. Jubilee (Syngenta Seeds Inc., Boise, ID) was planted in the greenhouse in $15-\mathrm{cm}-$ diameter plastic pots containing a steampasteurized 1:2:1 mixture of peat, perlite, and soil. Two seed were planted per pot and thinned to one plant per pot after 
emergence. The plants were fertilized weekly with a solution of 21-5-20 (N-P-K) fertilizer (200 ppm N; Miracle-Gro, Marysville, $\mathrm{OH})$.

Inoculum preparation and plant inoculation. P. stewartii isolate ES Rif-9A was obtained from Charles B. Block, United States Department of Agriculture (USDA) Plant Introduction Station, Iowa State University, Ames. This isolate is a rifampicin- and nalidixic acid-resistant strain derived form a wild-type strain of $P$. stewartii (SS104) (14). Stock cultures of this isolate were stored at $-75^{\circ} \mathrm{C}$ in $15 \%$ glycerol and, before experiments began, this strain was twice inoculated and recovered from sweet corn cv, Stowell's Evergreen, which is moderately resistant to $P$. stewartii. Studies by Lincoln $(15,16)$ have shown that $P$. stewartii strains that are inoculated repeatedly and recovered from resistant plants maintain their aggressiveness better than strains passed through susceptible plants. Isolate stability was confirmed by serial transfers onto nonselective media and by plant inoculation and re-isolation. No evidence of back mutation was observed (2). Prior to inoculation, cultures were incubated for $48 \mathrm{~h}$ at $25^{\circ} \mathrm{C}$ on nutrient broth yeast extract agar (NBY) amended with cycloheximide $(100 \mu \mathrm{g} / \mathrm{ml})$, rifampicin $(50 \mu \mathrm{g} / \mathrm{ml})$, and nalidixic acid (40 $\mu \mathrm{g} / \mathrm{ml}$ (NBY-CRN). Inoculum concentrations were adjusted to approximately 1 $\times 10^{8} \mathrm{CFU} / \mathrm{ml}$ in normal saline solution $(0.85 \% \mathrm{NaCl})$. At corn growth stage V5 (fifth-leaf stage), the second youngest leaf of each corn seedling was inoculated with $P$. stewartii (ES Rif-9A) using the pinprick method $(2,32)$ and plants were kept at a temperature between 18 and $21^{\circ} \mathrm{C}$. All plants were reinoculated 5 days later using the same procedure.

Collection of corn flea beetles. For both the acquisition and transmission feeding period experiments, bulk samples of corn flea beetles were collected using a 38.1-cm-diameter sweep net (Gempler's, Belleville, WI). Each bulk sample consisted of 30 to 60 sweeps within a corn plant canopy. Samples of field-collected corn flea beetles were separated from debris and other insects that were collected during field sampling by emptying the contents of a sample bag into a 5.6-liter plastic pan that contained approximately 3 liters of tap water. Individual corn flea beetles then were collected using a moistened, small-bristle paintbrush and transferred to insect cages as described below.

Acquisition experiments. For the acquisition experiments, there were six treatments (duration of the acquisition feeding period) and 45 replications or beetles per treatment. The acquisition treatment periods were $3,6,12,24,36,48$, and 72 h. After Stewart's disease symptoms were present on the inoculated leaves ( 7 to 9 days after inoculation), one fieldcollected corn flea beetle was placed in a cage consisting of a 2.5 -cm-diameter acrylic hollow rod that was approximately $2.5 \mathrm{~cm}$ long. The top end of the hollow transparent rod was sealed with a polyester mesh ( 32 by 32 per $2.5 \mathrm{~cm}$ ) and a circular sheet of armaflex insulation $(3.55 \mathrm{~cm}$ in diameter) was placed on the opposite end. This piece was affixed with two $1.25-\mathrm{cm}$ nails.

To quantify the relationship between acquisition feeding time and percent acquisition of $P$. stewartii by corn flea beetles, one corn flea beetle per cage was placed on a diseased corn leaf at the edge of $P$. stewartii lesions. A diseased leaf was one in which lesions typical of $P$. stewartii were observed along the leaf veins. Corn flea beetles were allowed to feed for the appropriate amount of time (treatments), then removed from the diseased seedlings. Upon removal, corn flea beetles were individually ground in $300 \mu \mathrm{l}$ of phosphatebuffered saline Tween buffer (PBST; $8.0 \mathrm{~g}$ of $\mathrm{NaCl}, 1.15 \mathrm{~g}$ of $\mathrm{Na}_{2} \mathrm{HPO}_{4}, 0.2 \mathrm{~g}$ of $\mathrm{KH}_{2} \mathrm{PO}_{4}, 0.2 \mathrm{~g}$ of KCL, $0.5 \mathrm{~g}$ of Tween 20 , and $1,000 \mathrm{ml}$ of $\mathrm{dH}_{2} \mathrm{O}, \mathrm{pH}$ 7.4) in an autoclaved microcentrifuge tube. Each beetle suspension $(100 \mu \mathrm{l})$ was spread onto duplicate plates of NBY-CRN agar to isolate the rifampicin-nalidixic acid-resistant isolate of $P$. stewartii. The bacterial cultures then were placed in an incubator at $25^{\circ} \mathrm{C}$. After $48 \mathrm{~h}$, the plates were examined for colonies typical of $P$. stewartii. Acquisition of $P$. stewartii by individual corn flea beetles was considered positive if the ES Rif9A strain was recovered from the NBY-CRN media. Pathogenicity tests were conducted to confirm that the colonies were P. stewartii. This was done by inoculating corn seedlings with individual isolates at corn growth stage V2 (second-leaf stage) using $1 \times 10^{8} \mathrm{CFU} / \mathrm{ml}$ in normal saline solution $(0.85 \% \mathrm{NaCl})$. Plants were observed for symptoms of Stewart's disease after 8 days. The acquisition experiments were performed three times.

Transmission experiments. Based on the results obtained from the acquisition study, the transmission study was conducted using a single acquisition feeding period of $48 \mathrm{~h}$. The 48 -h acquisition feeding period was chosen because more than $50 \%$ of the corn flea beetles $(63.3 \%)$ were predicted to have acquired $P$. stewartii after a 48-h acquisition feeding period (based on the acquisition experiments). In all, 270 corn flea beetles were placed individually in cages and allowed to feed for $48 \mathrm{~h}$ on diseased plants. Caged beetles then were transferred to healthy plants at corn growth stage V3 (third-leaf stage) and allowed transmission feeding periods of 3 , $6,12,24,36,48$, or $72 \mathrm{~h}$. Thirty beetles were tested individually for each feeding period. During the course of each experiment, a small number of corn flea beetles did not survive until the end of their respective transmission feeding periods; therefore, the corn seedlings receiving these beetles were omitted from the analysis. After the appropriate transmission feeding period, surviving beetles were removed and placed individually in sterile microcentrifuge tubes and ground in PBST buffer. Of the ground suspension, $100 \mu \mathrm{l}$ was placed onto NBY-CRN to determine if the corn flea beetles had acquired the rifampicin- and nalidixic acid-resistant strain of $P$. stewartii. The proportion of successful transmissions was operationally defined on the number of plants testing positive for $P$. stewartii divided by the number of corn flea beetles that had successfully acquired the bacterium within 48 h. Thus, plants receiving corn flea beetles that had not acquired $P$. stewartii after the 48-h acquisition feeding period were deleted from the analysis. This standardized value for pathogen transmission was used for modeling purposes.

After removal of the cages, corn leaves were examined carefully for corn flea beetle feeding scars. The leaves that had been exposed to feeding were sampled 7 days later by taking $0.3 \mathrm{~g}$ of leaf tissue in the area surrounding and including each feeding scar and grinding it individually in 800 $\mu \mathrm{l}$ of $1 \times$ PBST buffer (based on the sample weight). Leaf sap $(200 \mu \mathrm{l})$ obtained from the ground leaf samples was plated onto the NBY-CRN selective medium. Percent transmission of $P$. stewartii was operationally defined as the number of corn leaves that tested positive for $P$. stewartii based on recovery of the Rif9A strain from the selective media, divided by the total number of corn seedlings that had a corresponding live corn flea beetle that tested positive for the NBY-CRN-marked strain. Pathogenicity tests were conducted with these isolates as described previously. The transmission experiments were performed a total of three times.

Data analysis. Data from both the acquisition and transmission experiments for specific variables (e.g., percent acquisition at $6 \mathrm{~h}$, time to $50 \%$ acquisition, time to $50 \%$ transmission, percentage acquisition or transmission at $72 \mathrm{~h}$, and so on) were analyzed using analysis of variance and mean separations were performed using the Waller-Duncan K-ratio test $(P \leq 0.05$; Statistical Analysis System, SAS Institute, Gary, NC).

To select the most appropriate modeling approach, percent acquisition of $P$. stewartii by corn flea beetles was plotted with respect to acquisition feeding period for each acquisition experiment, and percent transmission of $P$. stewartii by corn flea beetles was plotted with respect to transmission feeding period for each transmission experiment (Sigma Plot; SPSS INC, Chicago, IL). Next, the change in percent acquisition (or transmission) (dy) with respect to the change in time (dt) was each plotted with respect to time (t) for each experiment. Based upon the shapes of the percentage of acquisition or transmission 
curves and their respective rate curves (dy/dt versus $t$ ), one or more population growth models were selected and evaluated for goodness of fit $(6,33)$. To accomplish this, pathogen acquisition and transmission data first were converted to proportions and then transformed using linearized models (logistic, linear, Gompertz, monomolecular, or logarithmic) that appeared to best fit these data $(6,13,20)$. The criteria used to select the best linearized model were (i) the $F$ test for each overall model, (ii) the coefficient of determination $\left(R^{2}\right)$, (iii) the standard error of the estimate for y (SEEy), and (iv) the T statistic for the slope (33). After selecting the most appropriate population growth model and transforming pathogen acquisition and transmission data, linear regression was performed for each experiment to estimate the intercepts and rates (slopes) for pathogen acquisition (or transmission) with respect to time, as well as to calculate regression statistics $(13,20,33)$. The resulting linear models from both the acquisition and transmission experiments were used to calculate the time to $50 \%$ acquisition or transmission by rearranging each equation to solve for the time (in hours) that $50 \%$ of corn flea beetles had acquired or transmitted the pathogen.

\section{RESULTS}

Acquisition experiments. The earliest measured acquisition of $P$. stewartii from diseased corn plants by corn flea beetles occurred the first within 3 to $6 \mathrm{~h}$ of feeding. The percentage of corn flea beetles that acquired $P$. stewartii after a 6-h acquisition access period ranged from 0 to $26.7 \%$. (Fig. 1A). Acquisition increased at the fastest rate from 12 to $36 \mathrm{~h}$, and the rate of acquisition then decreased between 36 and 72 h (Fig. 1A). After 72 h, the percentage of corn flea beetles that had acquired P. stewartii ranged from 68 to $94 \%$ (Fig. 1A).

Based upon the shape of the acquisition (Fig. 1A) and rate curves (Fig. 1B), the Gompertz model and the logistic population growth models were selected for further consideration to develop a linearized population growth model that best fit the acquisition experiments $(6,20)$. Based upon model selection criteria ( $F$ statistic, $R^{2}$, and so on), the linearized form of the Gompertz model was found to best fit the three acquisition experiments, with acquisition feeding period (X) explaining 91 to $99 \%\left(R^{2}\right)$ of the variation in percentage of acquisition (Y). The slopes (rates of acquisition) relating percent acquisition of $P$. stewartii by corn flea beetles to acquisition feeding period for the three experiments were $0.043,0.058$, and 0.022 gompits $/ \mathrm{h}$, respectively, which equates to an approximate rate of 1 to $2 \%$ acquisition per hour over the 72-h acquisition feeding period (with rates increasing fastest up to $37 \%$ acquisition and subsequently slowing after
$37 \%$ of the corn flea beetles had acquired the pathogen; Fig. 1C). The three experiments could not be combined into a single model because there were significant differences $(P \leq 0.05)$ among the slopes for the three individual experiments. The SEEy values for the three linearized acquisition curves were $0.38,0.15$, and 0.19 gompits, respectively. Using linear regression (Fig. 1C), the duration of the acquisition feeding period required for $50 \%$ of the corn flea beetles to acquire the rifampicinand nalidixic acid-resistant strain of $P$. stewartii from diseased corn plants was $49.8,29.2$, and $30.4 \mathrm{~h}$ for the three experiments, respectively. The average acquisition feeding period for $50 \%$ of the corn flea beetles to acquire $P$. stewartii was $36.5 \pm 11.6 \mathrm{~h}$.

Transmission experiments. The earliest measured transmission (11\%) from $P$. stewartii-infested corn flea beetles to corn
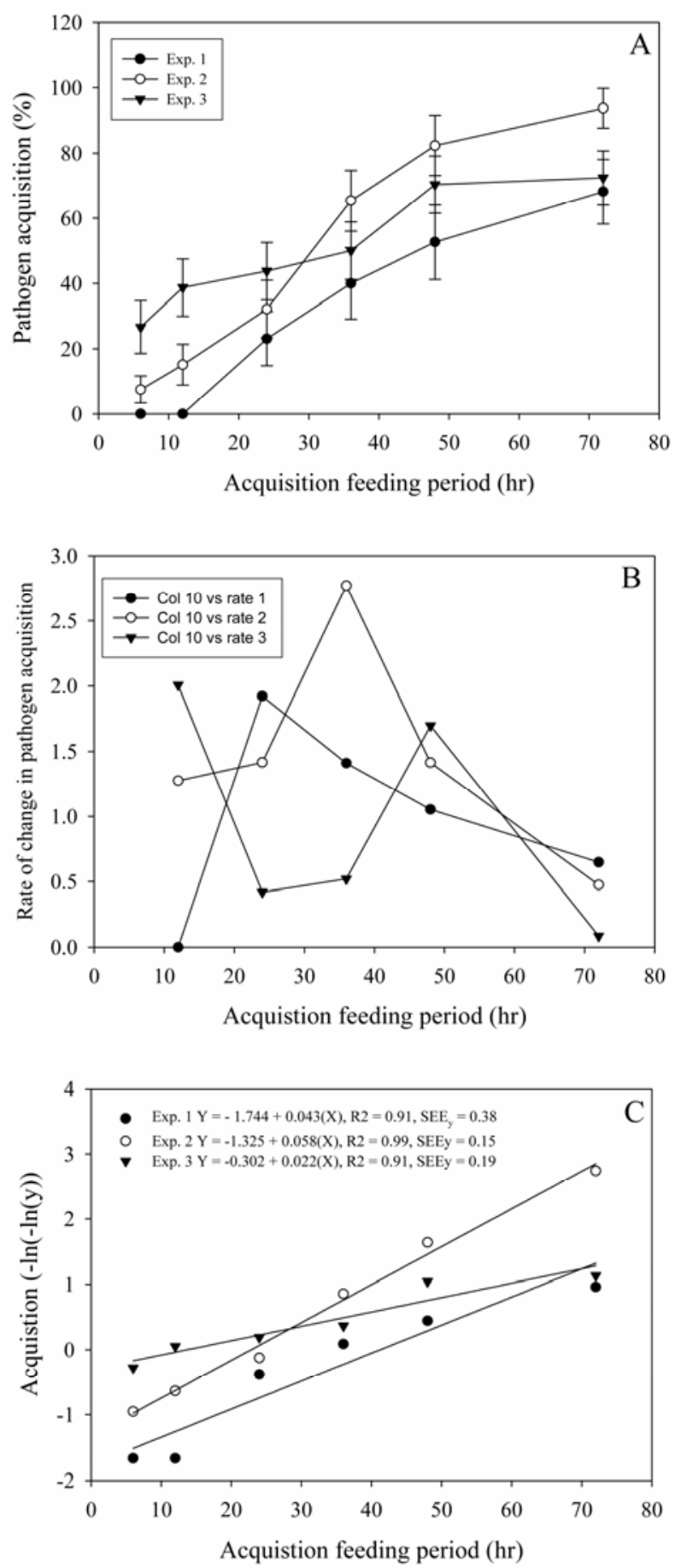

Fig. 1. A, Pathogen acquisition progress curves for corn flea beetles feeding on corn plants inoculated with a rifampicin- and nalidixic acid-resistant strain of Pantoea stewartii (isolate ES-Rif 9A). B, Rate of change in pathogen acquisition between consecutive acquisition feeding period time points. C, Linear regression lines and equations using the Gompertz model $(-\ln [\ln (\mathrm{y})])$ to transform the proportion of $P$. stewartii corn flea beetles that had acquired $P$. stewartii in response to increasing acquisition feeding period. 
seedlings occurred after a 3-h transmission feeding period in one experiment, and between 3 and $6 \mathrm{~h}$ in the other two experiments (38 and 50\% transmission, respectively; Fig. 2A). After a 48-h transmission feeding period, percent transmission of $P$. stewartii by $P$. stewartii-infested corn flea beetles to corn seedlings was close to $100 \%$ for all three transmission experiments (Fig. 2A). The rate (dy/dy versus t) of transmission of $P$. stewartii to corn seedlings by $P$. stewartii-infested corn flea beetles was fastest at the beginning of the transmission feeding period, then slowed
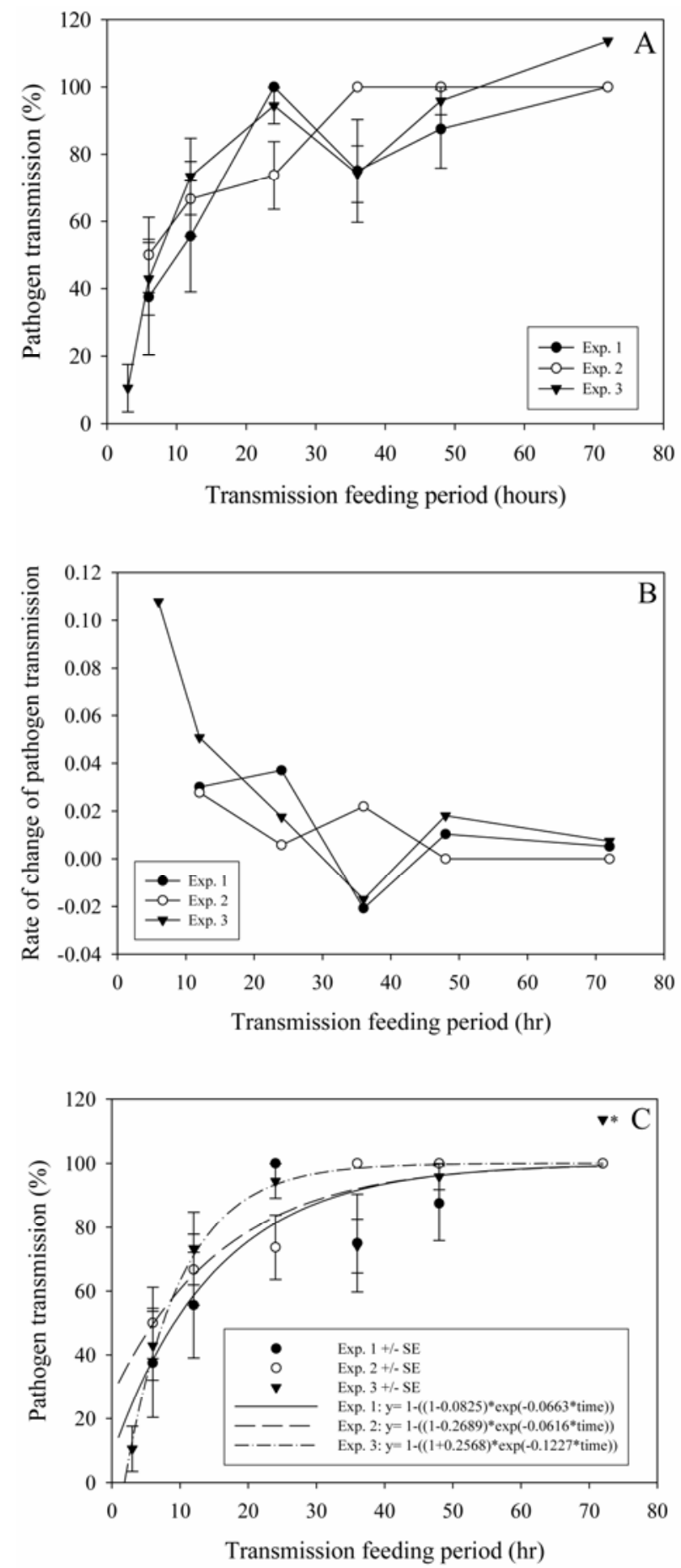

Fig. 2. A, Pathogen transmission progress curves for corn flea beetles feeding on corn plants inoculated with a rifampicin- and nalidixic acid-marked strain of Pantoea stewartii (isolate ES-Rif 9A) after feeding on healthy corn plants. B, Plot of the change in pathogen transmission with the change in transmission feeding time (transmission rate, dy/dt versus $\mathrm{t}$ ) with respect to time. The negative decrease in the rate is typical of data that is best fit with the monomolecular growth model. C, Plot of pathogen transmission curves with the fitted equations with the nonlinear form of the monomolecular growth model are presented. The value * represents the case for false negatives in corn flea beetles that tested negative for $P$. stewartii acquisition by corn flea beetles, even though a small number of corn seedlings tested positive for $P$. stewartii.

as transmission feeding periods increased, which is also characteristic of the monomolecular growth model (Fig. 2B) (6,20).

An initial examination of the linearized pathogen transmission data (using an assumption that the maximum transmission was $99.5 \%$ ) indicated that the linearized form of the monomolecular model performed well for two of the three transmission experiments. We found, however, that the nonlinear form of the monomolecular model better fit the percent transmission data for all three experiments (5). The nonlinear form of the monomolecular model is:

$$
y=1-\left[\left(1-y_{0}\right) * \exp (-r * \text { time })\right]
$$

where $y_{0}$ represents a constant of integration and $r$ represents the rate in units of time $^{-1}(5,6)$. A pseudo- $R^{2}$ value (1 $S S E / S S T O)$ and examination of residuals was used to verify the model fit for each experiment (28). Therefore, we used the nonlinear form of the model to quantify pathogen transmission with respect to time (Fig. 2C) (6). Pseudo- $R^{2}$ values ranged from 98.1 to $99.5 \%$, indicating a strong model fit. The rates of $P$. stewartii transmission using the nonlinear monomolecular model for each experiment were 0.07 , 0.06 , and 0.12 units/h, respectively (i.e., 7 , 6 , and $12 \%$ transmission per hour with the rate decreasing as time increases; Fig. 1A). Using the nonlinear monomolecular model, the predicted transmission feeding times required for $50 \%$ of $P$. stewartiiinfested corn flea beetles to transmit the pathogen to corn seedlings were 9.2, 6.2, and $7.5 \mathrm{~h}$ for the three experiments, respectively (mean: $7.6 \pm 0.87$ h; Fig. 2C). After approximately 20 to $35 \mathrm{~h}$ in each experiment, greater than $90 \%$ transmission was observed, after which there was only a slight change in percentage of transmission through $72 \mathrm{~h}$.

\section{DISCUSSION}

Vector efficiency is a complex process involving several subprocesses: (i) acquisition efficiency, (ii) transmission efficiency, and (iii) the period of time that the vector remains infectious. Each of these subprocesses may be influenced by vector biology, host resistance, and environmental conditions. This study is the first to quantify two of these subprocesses in the corn flea beetle- $P$. stewartii pathosystem: acquisition and transmission efficiency. Both of these subprocesses were affected by the length of the feeding periods for each subprocesses. Acquisition of $P$. stewartii by corn flea beetles first was detected after a 6-h acquisition feeding period with up to $24 \%$ acquisition. By $24 \mathrm{~h}, 24$ to $48 \%$ of the corn flea beetles in this study had acquired the marked strain (isolate ES Rif-9A), and the average time for $50 \%$ of the corn flea beetles to acquire the marked strain was 36.5 $\pm 11.6 \mathrm{~h}$. The rapid acquisition of $P$. stewartii by corn flea beetles is epidemiologi- 
cally important in this pathosystem because it has been reported that $P$. stewartii is not passed from adult corn flea beetles to eggs (7). Therefore, the first and second field generations of $C$. pulicaria that occur after the overwintering generation has completed their life cycles must acquire $P$. stewartii from diseased plants in the field (9).

To study the effects of insecticide seed treatments on corn flea beetle leaf feeding and transmission of $P$. stewartii to corn plants, Munkvold et al. (19) arbitrarily used an acquisition feeding period of 9 to 10 days for corn flea beetles to acquire $P$. stewartii from diseased corn plants. Based upon our models using the Gompertz transformation and extrapolating beyond 72 h ( 3 days) in our study to 9 or 10 days, as was used in Munkvold et al.'s study, we estimate that percent acquisition of $P$. stewartii by corn flea beetles was close to $100 \%$ and that an acquisition period of 6 to 7 days would actually be sufficient to obtain close to $99 \%$ acquisition. Using a different approach, Dill (7) also allowed corn flea beetles to feed on infected corn plants to determine the minimum amount of leaf tissue that corn flea beetles needed to consume before they could acquire the bacterium. The duration of the acquisition feeding period and the efficiency of acquisition with respect to acquisition feeding time, however, were not reported.

This study provides new quantitative information to explain how rapidly corn flea beetles can acquire and transmit P. stewartii from diseased corn plants in the field. Epidemiologically, the ability of $50 \%$ of corn flea beetles to acquire the pathogen within $36.5 \mathrm{~h}$ and for $50 \%$ of P. stewartiiinfested beetles to transmit $P$. stewartii within 6 to $8 \mathrm{~h}$ facilitates the rapid increase in pathogen inoculum in corn fields, as well as the rapid dissemination of that inoculum. The subprocesses of acquisition and transmission may contribute directly to the rapid increase in the incidence of $P$. stewartii-infested corn flea beetles (10) and the rapid temporal spread of Stewart's disease in the field. Under normal field conditions, the actual percentage of diseased plants resulting from the transmission of a fixed population size of P. stewartii-infested corn flea beetles may be higher than reported in our study, because corn flea beetles in the field can move readily from plant to plant, and a single infectious corn flea beetle may lead to multiple plant infections, although this hypothesis needs to be evaluated experimentally. Also, we did not test the possibility that percent transmission may increase in response to a longer acquisition access period. Our study was based on using a single acquisition access period ( $48 \mathrm{~h})$ to ensure that more than $50 \%$ of the corn flea beetles would be infested by $P$. stewartii, and the actual percentage of corn flea beetles that had successfully acquired $P$. stewartii for use in the three transmission feed- ing period studies was 72,71 , and $72 \%$, respectively.

Esker and Nutter (10) observed that the incidence of $P$. stewartii-infested corn flea beetles in the first summer generation was as high as 20 to $40 \%$ in newly emerged beetles. In that study, corn flea beetles were sampled and tested by enzyme-linked immunosorbent assay just after the beetlefree period that occurs in early-to-mid June. This is the period after which the overwintering corn flea beetles have completed their life cycle (and died), but before the first summer generation of corn flea beetles has emerged from eggs laid by the overwintering generation $(7,9)$. During the first 20 days that the first summer generation had begun to emerge (day of year 180 to 200), the proportion of P. stewartiiinfested corn flea beetles increased at a rate of 1.2 to $3.3 \%$ per day (10). Although the present study found the rate of acquisition by corn flea beetles to be 2 to $3 \%$ per hour (not days), our study does not include information concerning the probability that corn flea beetles will come into contact with and feed on P. stewartii-infected leaf tissue. In the present study, corn flea beetles were placed directly into contact with P. stewartii-infected leaf tissue. Esker and Nutter (10) further reported that, in spite of beetle death at the end of the first summer generation and the emergence of the second corn flea beetle summer generation, the incidence of $P$. stewartii-infested corn flea beetles in the second summer generation was as high as $85.6 \%$ by late August. Thus, our findings that corn flea beetles can rapidly acquire $P$. stewartii supports field observations by Esker and Nutter (10) regarding the rapid increase in $P$. stewartiiinfested corn flea beetle populations during the corn growing season. Moreover, our study is the first to report that the Gompertz population growth model best describes $P$. stewartii acquisition by corn flea beetles over time and explains how $P$. stewartii-infested corn flea beetle populations can reach incidence levels as high as $85.6 \%$ in the field.

Whether or not there is a true latent period required within the corn flea beetle vector before transmission can occur remains unknown. However, the fact that we did not detect the presence of $P$. stewartii after a 3-h acquisition feeding period, but did observe up to $24 \%$ acquisition of $P$. stewartii by corn flea beetles after a 6-h acquisition feeding period, suggests that either corn flea beetles did not acquire a sufficient number of bacterial cells to be detected after a 3-h acquisition feeding period (using our operational definition for successful acquisition that requires the recovery of the marked strain from corn flea beetles using a selective medium), or that the bacterium must multiply within the corn flea beetle to reach a population level that could be detected using our detection method. Dill (7) believed that re- gurgitation or defecation on the leaf surface was needed before successful transmission of $P$. stewartii could occur near corn flea beetle feeding scars. In our study, the fact that up to $24 \%$ ( 0.24 probability) of the corn flea beetles could acquire $P$. stewartii after a 6-h acquisition feeding period and that up to $11 \%(0.11$ probability) of $P$. stewartii-infested corn flea beetles could successfully transmit the pathogen after a 3-h transmission feeding period indicates that it is possible for $2.64 \%(0.11 \times 0.24 \times 100)$ of corn flea beetles to acquire and transmit $P$. stewartii in $6 \mathrm{~h}$ or less. Thus, if a latent period is required within the feeding periods of acquisition and transmission, it is less than $6 \mathrm{~h}$. Moreover, the efficiency of both subprocesses increases with increasing feeding time.

We did not examine the length of time that $C$. pulicaria remains infectious (retention time); however, previous studies by Robert et al. (27) and Dill (7) have postulated that corn flea beetles remain infectious throughout a single generation once they have acquired the bacterium. Although it is likely that $C$. pulicaria can acquire $P$. stewartii and transmit it to more than one plant, additional experiments are needed to determine how long P. stewartiiinfested corn flea beetles remain infectious and how long they remain feeding on a single corn plant before moving to other corn plants.

In the transmission study, there was a positive relationship between the duration of the transmission feeding period and the increase in percent transmission of $P$. stewartii. It is important to note that, although percentage transmission increased as the transmission feeding period increased, the rate of transmission (dy/dt versus t) actually decreased as the transmission feeding period (X) increased in all three experiments. This study is the first to report that percent transmission of $P$. stewartii by corn flea beetles is best described by the monomolecular model. According to this model, percent transmission of $P$. stewartii increases the fastest at the beginning of the transmission feeding period and the rate of transmission decreases with respect to time without an inflection point. Thus, biologically, corn flea beetles (as a population) tend to transmit $P$. stewartii more efficiently early in the postacquisition phase than later in the postacquisition phase.

Following an acquisition access period of $48 \mathrm{~h}$ on diseased plants, the minimum transmission feeding period required for successful transmission of $P$. stewartii by corn flea beetles was $3 \mathrm{~h}$, and $50 \%$ transmission occurred by $7.6 \pm 0.87 \mathrm{~h}$. Thus, corn flea beetles are highly efficient in both acquiring and transmitting $P$. stewartii and, combined with the supposition that corn flea beetles remain infectious for the remainder of their adult lives, this makes 
the corn flea beetle a highly efficient vector. Our results suggest that insecticide seed treatments and foliar insecticides must act quickly to prevent corn flea beetles from acquiring and transmitting $P$. stewartii. Furthermore, our results suggest that the development of resistant corn hybrids that effectively reduce or delay pathogen acquisition and transmission may offer an extremely effective measure to better mange Stewart's disease in the future.

We observed nontransmission of $P$. stewartii by corn flea beetles that were known to be carrying $P$. stewartii (based on positive tests for $P$. stewartii by plating beetle contents on NBY-CRN media). Nontransmission by infested corn flea beetles could be due to factors such as insufficient feeding times (in cages) to transmit the bacterium, the need for a period of latency in the corn flea beetle before it becomes infectious, the possibility that injury to beetles occurred when transferring them from diseased to healthy plants, or a required prolonged settling time for some caged beetles to initiate feeding.

\section{ACKNOWLEDGMENTS}

We thank the following companies for providing financial support for this project: Pioneer Hi-Bred International Inc., Monsanto Inc., Syngenta Crop Protection Inc., and Gustafson Inc. This research also was supported by grants from the Iowa State University Center for Advanced Technology Development and the USDA North Central IPM Grants program, Project No. 2001-41530-01104. We thank J. Obrycki (entomologist) for the cage design and input on these studies; J. Guan and A. Moreira for their technical assistance in conducting the experiments; and E. Braun, M. Gleason, and D. McGee for their reviews and comments regarding this manuscript.

\section{LITERATURE CITED}

1. Blanco, M. H., Johnson, M. G., Colbert, T. R. and Zuber, M. S. 1977. An inoculation technique for Stewart's wilt disease of corn. Plant Dis. Rep. 61:413-416.

2. Block, C. C. 1996. Biology of seed transmission of Erwinia stewartii in maize. Ph.D. dissertation, Iowa State University, Ames.

3. Block, C. C., Hill, J. H., and McGee, D. C. 1998. Seed transmission of Pantoea stewartii in field and sweet corn. Plant Dis. 82:775-780.
4. Block, C. C., Hill, J. H., and McGee, D. C. 1999. Relationship between late-season severity of Stewart's bacterial wilt and seed infection in maize. Plant Dis. 83:527-530.

5. Campbell, C. L. 1999. Disease progress in time: modelling and data analysis. Pages 181206 in: The Epidemiology of Plant Diseases, D. G. Jones, ed. Kluwer Academic Publishers, Dordrecht, The Netherlands.

6. Campbell, C. L., and Madden, L. V. 1990. Introduction to Plant Disease Epidemiology. John Wiley \& Sons, New York.

7. Dill, J. F. 1979. Biology and management of the corn flea beetle, Chaetocnema pulicaria Melsheimer, relative to the incidence of Stewart's disease in corn. Ph.D. dissertation, Purdue University, West Lafayette, IN.

8. Elliot, C., and Poos, F. W. 1934. Overwintering of Aplanobacter stewartii. Science 80:289290.

9. Esker, P. D., and Nutter, F. W., Jr. 2002. Temporal distribution of Chaetocnema pulicaria (Coleoptera: Chrysomelidae) populations in Iowa. J. Econ. Entomol. 95(4):739-747.

10. Esker, P. D., and Nutter, Jr., F. W. 2003. The temporal dynamics of corn flea beetle populations infested with Pantoea stewartii, the causal agent of Stewart's disease of corn. Phytopathology 93:210-218.

11. Frutchey, C. W. 1936. A study of Stewart's disease of sweet corn caused by Phytomonas stewartii. Mich. Agric. Exp. Stn. Tech. Bull. 152.

12. Khan, A., Ries, S. M., and Pataky, J. K. 1996. Transmission of Erwinia stewartii through seed of resistant and susceptible field and sweet corn. Plant Dis. 80:398-403.

13. Labrinos, J. L., and Nutter, F. W., Jr. 1993. Comparative effects of a protectant versus a sterol inhibiting fungicide on disease components of late leafspot of peanut. Plant Dis. 77:837-845.

14. Lamka, G. L., Hill, J. H., McGee, D. C., and Braun, E. J. 1991. Development of immunosorbent assay for seedborne Erwinia stewartii in corn seeds. Phytopathology 81:839-846.

15. Lincoln, R. E. 1939. Host-parasite interactions with bacterial wilt of maize. Science 89:159160 .

16. Lincoln, R. E. 1940. Bacterial wilt resistance and genetic host-parasite interactions in maize. J. Agric. Res. 60:217-239.

17. Mergaert, J., Verdonck, L., and Kersters, K. 1993. Transfer of Erwinia ananas (synonym, Erwinia uredovora) and Erwinia stewartii to the genus Pantoea emend. as Pantoea ananas (Serrano 1928) comb. Nov. and Pantoea stewartii (Smith 1898) comb. nov., respectively and description of Pantoea stewartii subsp. nov. and Pantoea stewartii (Smith 1898) comb. nov., respectively and description of Pantoea stewartii subsp. nov. Int. J. Syst. Bacteriol. 43:162-173

18. Michener, P. M., Pataky, J. K., and White, D. G. 2002. Rates of transmitting Erwinia stewartii from seed to seedlings of a sweet corn hybrid susceptible to Stewart's wilt. Plant Dis. 86:1031-1035.

19. Munkvold, G. P., McGee, D.C., and Iles, A. 1996. Effects of imidacloprid seed treatment of corn on foliar feeding and E. stewartii transmission by the corn flea beetle. Plant Dis. 80:747-749.

20. Nutter, F. W., Jr. 1997. Quantifying the temporal dynamics of plant viruses: a review. Crop Prot. 16:603-618.

21. Pataky, J. K., Du Toit, L. J., Kunkel, T. E., and Schmitt, R. A. 1995. Severe Stewart's wilt in central Illinois on sweet corn hybrids moderately resistant to Erwinia stewartii. Plant Dis. 79:104.

22. Pepper, E. H. 1967. Stewart's wild of corn. Monograph No. 4. The American Phytopathology Society, St. Paul, MN.

23. Rand, F. V. 1923. Bacterial wilt or Stewart's disease of corn. Canner 56:164-166.

24. Rand, F. V., and Cash, L. C. 1921. Stewart's disease of corn. J. Agric. Res. 21:263-264.

25. Rand, F. V., and Cash, L. C. 1924. Further evidence of insect dissemination of bacterial wilt of corn. Science 59:67-69.

26. Rand, F. V., and Cash, L. C. 1933. Bacterial wilt of corn. USDA Tech. Bull. 362:1-22.

27. Robert, A. L., Jenkins, M. T., Findley, W. R., Jr. 1953. Helminthosporium turcicum, Helminthosporium maydis, and Bacterium stewartii leaf blight ratings on corn at the Plant Industry Station, Beltsville, MD (mimeo.). Division of Cereal Crops and Diseases, Plant Industry Station, Beltsville, MD.

28. Schabenberger, O., and Pierce, F. J. 2002. Contemporary Statistical Models for the Plan and Soil Sciences. CRC Press, Boca Raton, FL.

29. Smith, E. F. 1909. Corn as a means of disseminating Bacterium stewartii. Science 30:223-224

30. Smith, E. F. 1914. Stewart's disease of sweet corn (maize). Pages 89-147 in: Bacteria in Relation to Plant Diseases. Carnegie Institute of Washington, Washington, D. C.

31. Stewart, F. C. 1897. A bacterial disease of sweet corn. New York Agric. Exp. Stn. Bull. 130:422-439.

32. Wallin, J. R., Loonan, D.V., and Gardner, C.A.C. 1979. Comparison of techniques for inoculating corn with Erwinia stewartii. Plant Dis. Rep. 63:390-392.

33. Webb, D. H., and Nutter, F.W., Jr. 1997. Effect of temperature and duration of leaf wetness on two disease components of alfalfa rust on alfalfa. Phytopathology 81:946-950 